\title{
Botswana's Greatest Challenge beyond the Successful Decline in Total Fertility Rate
}

\author{
Brothers Wilright Malema \\ Department of Economics, Faculty of Social Sciences, University of Botswana, Gaborone, Botswana \\ Email:malemabw@mopipi.ub.bw
}

How to cite this paper: Malema, B.W. (2020) Botswana's Greatest Challenge beyond the Successful Decline in Total Fertility Rate. Open Access Library Journal, 7: e5971. https://doi.org/10.4236/oalib.1105971

Received: December 2, 2019

Accepted: December 6, 2020

Published: December 9, 2020

Copyright (ङ 2020 by author(s) and Open Access Library Inc.

This work is licensed under the Creative Commons Attribution International License (CC BY 4.0).

http://creativecommons.org/licenses/by/4.0/

\begin{abstract}
The paper gives a narration of the change of Botswana's population age structure and a brief account of its economy. The part before the conclusion seeks to use figures or graphs to analyse the country's prospects in capitalising on the window of opportunity in order to drive economic growth and development.
\end{abstract}

\section{Subject Areas}

Demography, Socioeconomics

\section{Keywords}

Botswana, Demographic Dividend, Economy

\section{Introduction}

Botswana is probably one of the few countries in sub Saharan Africa to experience the demographic dividend. While this by itself is an opportunity to transform the economy from an upper middle economy to high income economy, such comes with great challenges. The country's problems of unemployment, poverty and income inequality amongst others need urgent attention. These three challenges are very much related and possibly self-reinforcing. The country's success in capitalising on the window of opportunity may be instrumental in addressing these challenges. These problems are not unique to Botswana but are observed globally with others thinking that inequalities might be increasing within and between economies or countries [1].

The state of the world population report's foreword focuses on inequality and its debilitating effects. It is indeed a world of two extreme cases of abundance on 
the one hand and desperate lack on the other. In this foreword, the late Dr Babatunde Osotimehin contrasts the billions at the bottom who are denied access to human rights and a better life while at the top the resources are expanding in an explosive mode for the rich of this world ensuring that the inequality gap continues to grow in contrast to the vision espoused within the Universal declaration of human rights. While the inequalities are often centred on the economic aspects of wealth and incomes, the reality is that they touch on many areas of humanity including social, political as well as institutional dimensions. The gender inequality and inequality in access to sexual and reproductive health if unattended remain a threat to the female race. Girls and women will continue in poverty and be denied access to human rights. In developing countries where such gaps are profound, the lack of access to family planning is one impediment to the progress of women as it may deny them access to education and paid employment against may multifaceted denials. This may further aggravate their exclusion and perpetuate their poverty [2].

While the economic disparities rank Botswana so unfavourably globally as it is in the bracket of the three most unequal societies in the world, the country has since independence strived to avail family planning freely to all. It is through this particular dispensation and the provision of free education that Botswana has been able to be in forefront along with a few African countries in realising the demographic dividend window of opportunity. It should however be borne in mind that the provision of family planning without the commensurate education for a better appreciation of such a provision may be unprofitable. Having children has in many primitive societies been both a source of investment and old age security as well as status, particularly if such children were taken care of very well. With this mind-set within societies, it would be difficult for family planning which goes against the norm to be embraced without questions. The most effective means to break this thinking would certainly be to allay the fears that without many children one has failed in both investing and insuring and that one's status may be enhanced by the absence of many children and actually boosted by the existence of a few. The ability to provide education and employment opportunities is critical in breaking this long held view which has most probably cut across all societies of the world.

Following the attainment of independence, Botswana put sexual reproductive health at the centre and promoted it through education in clinics and provided the necessary family planning services and resources at most of the government health facilities at no cost. The country was fortunate in that though one of the poorest countries in the world at the time of independence, the country had unmined diamonds which were kept a secret prior to independence [3]. The mining of diamonds in the early 1970s accorded the country the financial power so often lacking in developing countries. It was this power coupled with the visionary leadership of the founding fathers of the nation, anchored on the democratic system of governance which set Botswana apart from many within the 
continent. It should be borne in mind that Botswana is not the most resource endowed country in the continent, and many such countries blessed with immense resources were not able to capitalise on their resourcefulness for a number of reasons. It is compelling for one to think and conclude that the uniqueness of Botswana was in embracing modern democracy, founded on the country's traditional governance system of the kgotla that the country was able to avoid strife which characterised the broader continent. This traditional system allowed for the gathering of the village and tribe at gazetted places often referred to as kgotla, for the exchange of ideas and embraced the free expression of views by all in attendance. In principle and in theory, such a system was not exclusive, but in practice it might have been, as is the case in the modern democratic dispensation, where others are excluded by the circumstances in which they find themselves.

Botswana was able to use her resources in socio-economic investments, particularly education, health and infrastructure. With a small population of less than one million at the time, those who went to secondary in particular upper secondary will able to get easily absorbed in employment. By the 1990s those who graduated from tertiary institutions were almost guaranteed employment. The country was catapulted from being one of the poorest countries in the world at the time of independence to an upper middle income economy within forty years of her independence.

This following section of the paper reviews the drivers of the demographic dividend. Following that the paper gives a narration of the change of Botswana's population age structure and a brief account of its economy. The part before the conclusion seeks to use figures or graphs to analyse the country's prospects in capitalising on the window of opportunity in order to drive economic growth and development.

\section{Drivers of the DD}

The wheels below (Figure 1) are considered cardinal in realising the dividend and a brief discussion of their role is undertaken. This paper as early stated seeks to underlie the significance of governance in influencing the realisation of the dividend. The role of the DD in driving economic growth cannot be overemphasised as attested to by the experience of the Asian Tigers and subsequent to that Latin America [4] [5]. This experience has created anxiety on how the combined wheels will affect the realisation of the dividend within Sub Saharan Africa. The combination of the increasing proportion of working age population relative the economically inactive population and the implementation of successful key national policies have helped Brazil and Thailand to realise the dividend [5]. These authors further note that the demographic transition does not unleash the dividend on its own. There is a need for complementary initiatives in the form of economic policies, health, education and governance and political will for the dividend to be reaped. 


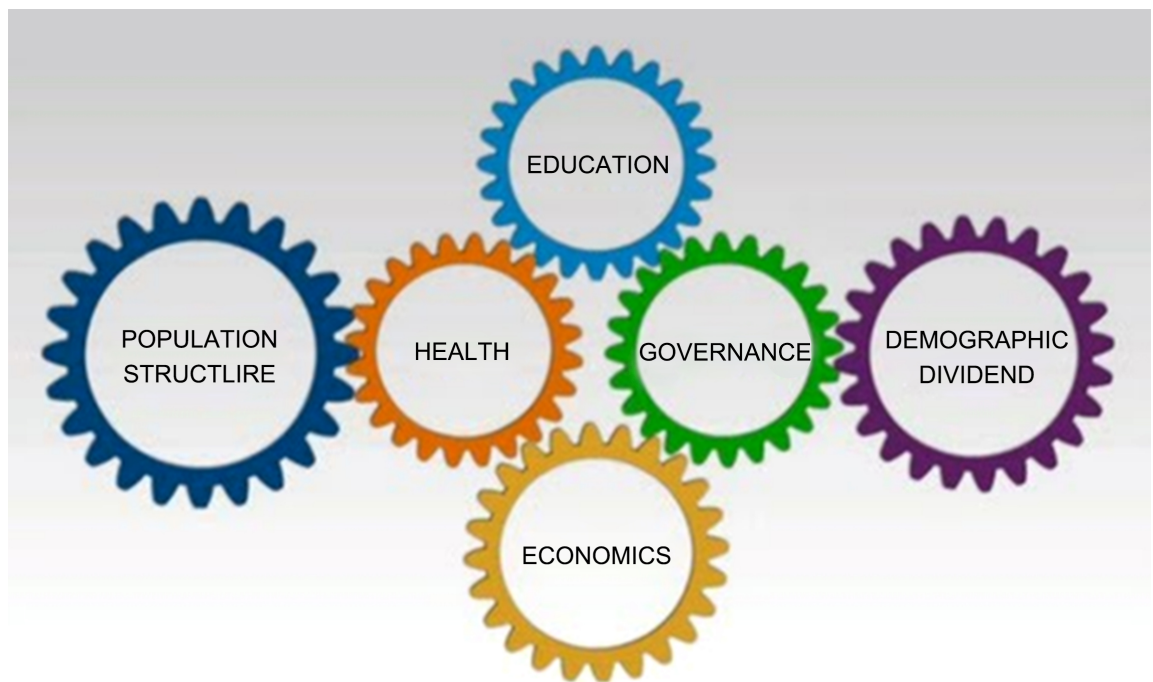

Figure 1. Drivers of the dividend.

\subsection{Human Capital}

In the economic development literature, both health and education are considered cores in the development of human resource or capital. Though distinctively different in their own right, I have combined the two under human capital since they are its primary determinants and by extension drivers of economic growth and development. It is important to note that both happen to the same person and just like income may be distributed unequally [1]. The two could possibly be considered escape routes from poverty in an environment of abundant job opportunities.

Health is quite important for wellbeing and increases in productivity whereas education is cardinal for a rewarding and satisfying life, absorption of modern technology, self-sustaining growth and development. Both depend on each other as educational performance is influenced by the health of an individual. A healthy individual is likely to perform relatively better than an unhealthy individual holding all things constant. An educated person is also likely to enjoy relatively better health than one not educated. Their combination is therefore critical for the expansion of human capabilities and by extension economic growth and development. A country that seeks to capitalise on harnessing the dividend will be better positioned to do so if it gives these two areas adequate attention.

\subsection{Economic Policies}

Economic policies are central to the realisation of the dividend occasioned by the change in the population structure. Along with human resource investment, relevant economic policies are a must for the working age group to be of value addition to the economy. Unless the bulging working age population has opportunities for employment and income earning opportunities, economic growth may prove elusive. A wide range of policies including trade policies, tax incentives and basic infrastructure development are some key policy options for driv- 
ing economic growth [5]. It needs to be borne in mind that trade liberalisation may actually accentuate unemployment and poverty [6]. They further assert that the flexibility of wages both upwards and downwards is considered important in reaping the dividend and minimum wages above the market rate could be detrimental to harnessing the dividend. The lack of openness and poor economic policies are perceived to be at the centre of Africa's dismal economic performance over the period 1965-1990 for a sample of countries [7]. A study conducted amongst nine SADC countries revealed that education levels and income inequality were key determinants of unemployment in that high inequality led to high unemployment and high levels of education reduced unemployment with corruption being detrimental to youth employment [8].

\subsection{Governance}

Good governance is very critical in promoting investment and attracting foreign investment within the economy as investors would need the confidence to know that the law is robust enough to ensure that contracts are strictly adhered to and their investments are secure. The rule of law is also important in dealing with issues of corruption and in having an efficient government necessary for the promotion of economic growth and development as well as gender equity [5]. Additionally they point out that during its transition South Korea had a strong central government which came up with comprehensive and integrated development plans running into decades. They also note the need for improvement in efficiency and effectiveness of government institutions in which inefficiencies are often reflected by government instability, corruption and inefficient bureaucracies of which the collective effect is widespread unemployment. The institutional relevance in the realisation of the dividend is also echoed by [7].

\section{Botswana and the DD}

The country is considered to be right at the centre of the dividend having entered the window of opportunity prior to 1990 and having reached the peak of the first dividend in 2008. The window is said to be diminishing [9].

\subsection{Botswana's Age Structure}

As earlier stated, Botswana is currently in the window of opportunity as attested to by the ever transforming population pyramids below. This shouldn't however, be construed to mean that Botswana is without challenges when it comes to sexual reproductive issues. There are still cases of high fertilities particularly within poor sections of society and even within the educated there are cases of unplanned pregnancies. School dropouts due to unplanned pregnancies are also very much worrisome and a lot of gaps are in existence which needs to be addressed. The ever emerging economic conditions of unemployment and stubborn inequalities might be the impediment to low levels of fertility across the different groups still struggling with unwanted pregnancies. The positive economic transformations 
of lives might hold the key to resolving the outstanding challenges still faced, rather than the pursuit of family planning. Lack of economic opportunities could be key in explaining this outstanding puzzle. The need for pro poor policies is necessary in addressing these imbalances across different population groups. There is evidence of the effect of socio-economic conditions in affecting the reproductive behaviours of different groups and the need for promotion of equity is viewed as a betterment elixir in addressing the challenges faced by the under privileged members of societies as observed in Malawi [5].

The pyramids (Figures 2-5) clearly show that there is a transformation in terms of the population structure of the country. Those of working age have been increasing since 1981 and it is logical to expect a more profound dominance of this group in the expected 2021 national population census.

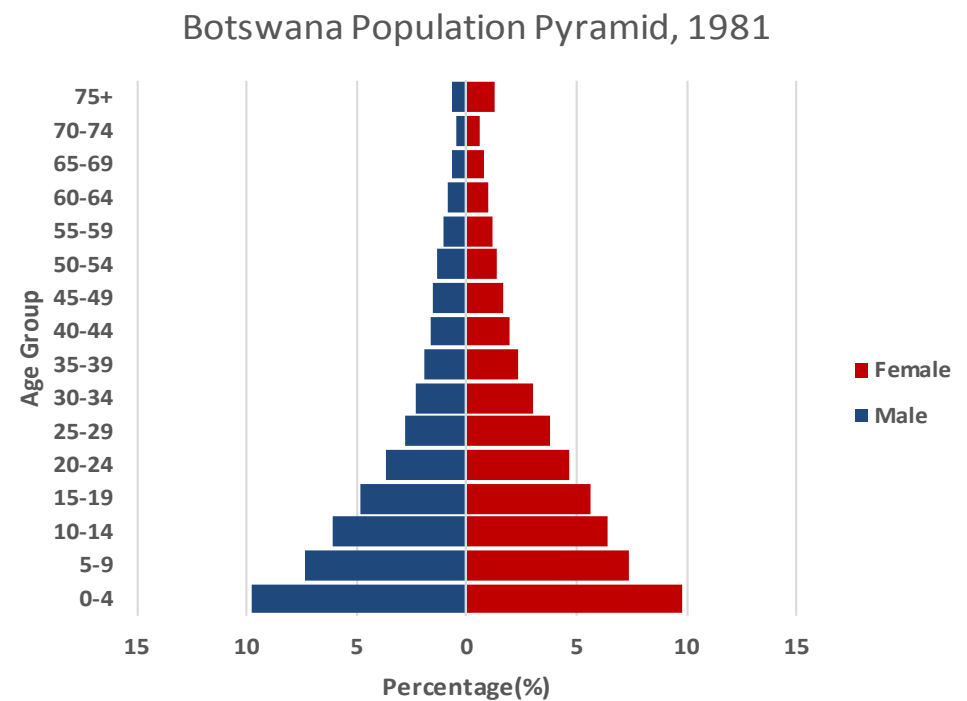

Figure 2. Botswana population pyramids for the years 1981 and 1991.

\section{Botswana Population Pyramid, 1991}
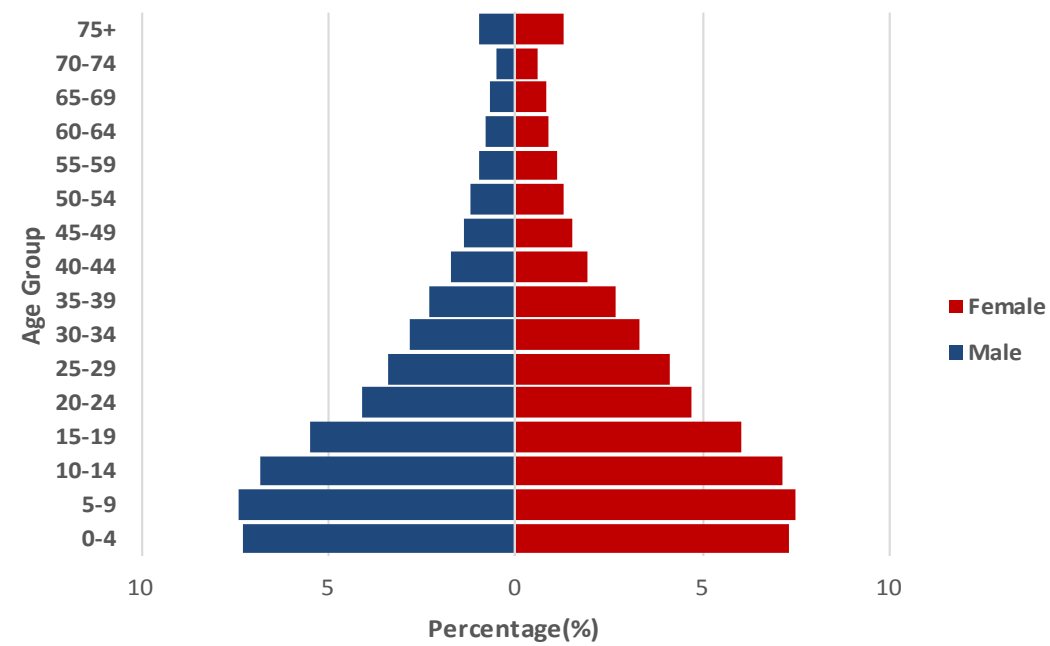

Figure 3. Botswana population pyramids for the years 1991. 


\section{Botswana Population Pyramid, 2001}

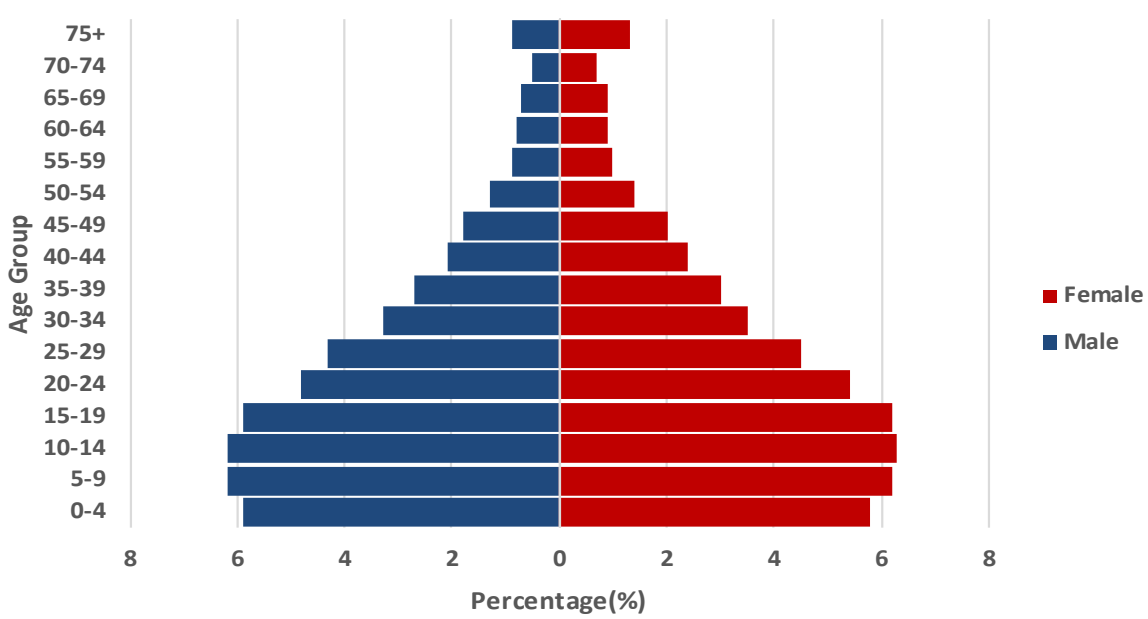

Figure 4. Botswana population pyramids for the years 2001.

\section{Botswana Population Pyramid, 2011}

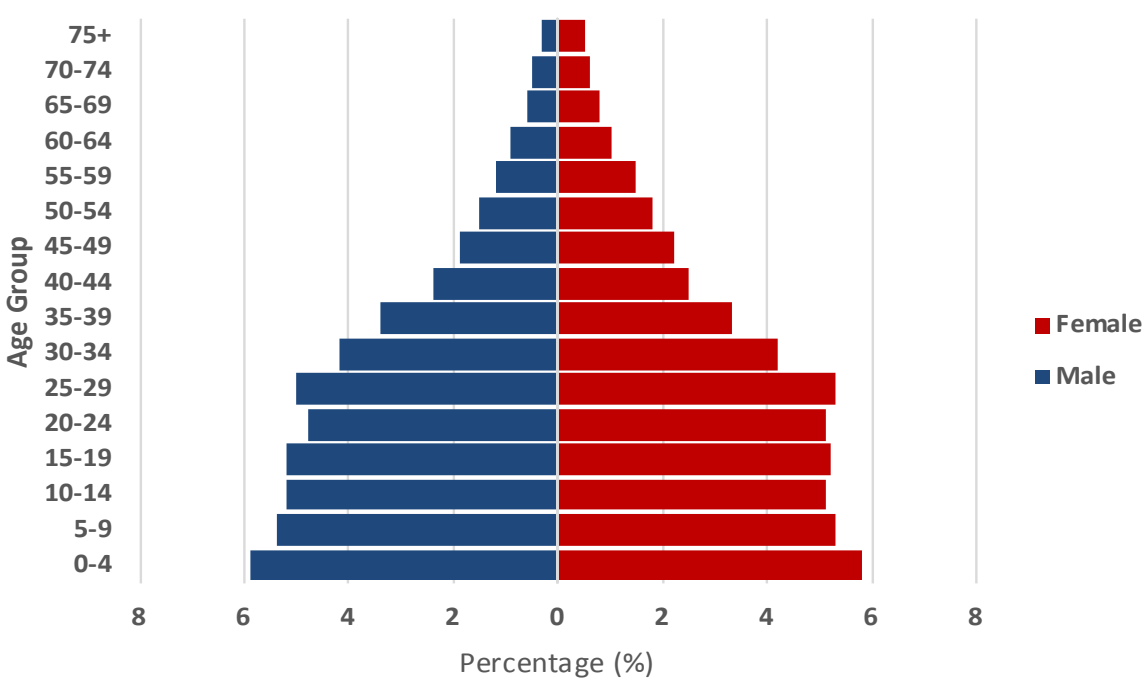

Figure 5. Botswana population pyramids for the years 2011. Source: Statistics Botswana, 2016. Selected Statistical Indicators 1966-2016; Enabling Stakeholders formulate policies, plan and make decisions.

This trajectory could be explained by the decline in fertility post-independence, which was driven largely but government efforts.

Botswana's Total Fertility Rate Trajectory Post Attaining Independence in 1966

Since attaining independence in 1966, Botswana has made significant progress in sexual and reproductive health, specifically in ensuring that individuals are able to decide if and when to have children through enabling access to family planning commodities. This progress was facilitated by a number of key strategic decisions including:

The Maternal and Child Health/Family Planning Programme 
The introduction and implementation of a high impact programme, the Maternal and Child Health/Family Planning (MCH/FP) through the Primary Health Care (PHC) model in 1973. The integration of FP into the PHC model proved beneficially in maximising the availability of family planning services through harnessing the nationwide network of healthcare facilities which were within 8 15 kilometres reach of $84 \%$ potential clients [10]. To strengthen the implementation of the programme, a number of key actions were taken;

- Capacity building of a wide ranging pool of health professionals were intensively upskilled on family planning clinical skills, family life education, integration of MCP/FP and outreach services, supply and logistics management, home visits among others.

- Guidelines and services standards, to facilitate the implementation of the programme were developed.

- A logistics manual for management of contraceptive commodities was developed to facilitate availability of contraceptives at national and health facility level.

Through these efforts, the total fertility rate in the country declined from 6.5 births per woman in 1971 to 5.2 births per woman in 1991 [11]. Further, where it is common knowledge that the unmet need for FP affects urban and rural dwellers disproportionately; an encouraging observation was that the decline in TRF occurred at an equal rate regardless of geographical location. That is, the TRF decreased from 5.3 and 6.6 to 4.6 and 5.9 births per woman for urban and rural dwellers respectively between 1971 and 1991 .

Pursuing the Agenda of the International Conference on Population and Development (ICPD)

Consistent with the need to respond appropriately and adequately to Programme of Action of the ICPD of 1994, the MCH/FP was reformed and mandated in 2002 as the SRH Division under the auspice of the Department of Public Health within the Ministry of Health with four operational units namely; Family planning, Adolescent SRH, Maternal and Newborn Care and Monitoring and Evaluation.

The impacts of the strategic investments into $\mathrm{SRH}$ with a focus on family planning in Botswana have been well documented and these include:

- The TFR of the country continued to decline from 5.2 births per woman to 3.1 births per woman in 2017 while CPR among married women of reproductive age is estimated at $65 \%$ [12].

- The proportion of teenagers aged 15 - 19 who are mothers decreased from an estimated $23.7 \%$ in 1988 to $9.7 \%$ in 2007 and the contraceptive prevalence rate (CPR) increased substantially from $30 \%$ among women of reproductive ages in 1984 to $53 \%$ in 2007 [13].

- Knowledge on at least one family planning method increased from $75 \%$ in 1984 to $98.3 \%$ in 2007 among women of reproductive ages. This increase in knowledge further manifested in the decline in the use of traditional methods for family planning from $8 \%$ in 1984 to 2.65 in 2007 [14]. 
Ultimately, these efforts may be greatly credited for the TFR decline that ensued, a factor which ushered Botswana into a demographic transition thus opening a window of opportunity in the early 1990s for the country to reap a demographic dividend.

\subsection{Botswana Economy}

The African continent is well endowed with natural resources. The continent has not been able to transform such endowment to any meaningful economic gains for the majority of its population, most of who are living under appalling conditions of poverty. In this paper the focus is in assessing the role of governance and political leadership in driving the dividend. It is the approach of this paper to combine the two into governance as the governance structures are largely a result of political factors.

The wheels discussed above are important in realising the dividend and in view of the author most of these wheels are anchored on the efficiency of governance. It is upon this view that this paper seeks to interrogate the role of governance in helping Botswana attain the dividend of this demographic transition. Botswana has been perceived as an island of peace at the time when strife was the order of the day in the sub region. The country had at some point experienced the fastest growing economy in the world and this and other economic successes endeared the country to be seen as "An African Economic Miracle". These accolades are in recognition of the country's positive efforts in striving for a betterment of the welfare of its citizens [15]. The country's gross domestic product per capita is currently in the region of US\$8000 and it is classified as a middle income economy.

The country has invested in human resource through the avenues of education and health since independence. While the necessary infrastructure and facilities have been availed, the qualities of the services rendered have been questioned. Botswana's unemployment stands at 17.8 percent and one problem attributable to this amongst many is the alleged mismatch between skills of graduates and the labour market demands of the economy. This seeks to posit that the job openings are available but there is paucity or required skills to fill these job opportunities. This to some degree contravenes former president HE SKI Khama who has consistently alluded in his state of the nation addresses that the economy was struggling to create adequate job opportunities for the unemployed. There also seem to be a lack of significant evidence that the country has had to rely on imported expertise for certain cadres within the economy. Such mismatch though now widespread seems to lack empirical evidence. However, it is critical to note that the labour force demands of any economy can never be static as they are subject to the economic dynamics which are propagated by economic structural changes over time. This necessitates a change in the educational system to ever produce the expertise required by the economy at any given time so as to capitalise on economic opportunities that may arise or even to help create an economy with such opportunities. South Korea had to shift education- 
al policy from compulsory primary education to an education system that focused more on the provision of skills and knowledge required for economic development [5].

\subsection{Botswana's Prospects}

Now that the country is in the window of opportunity, we seek to analyse the prospects for the country/s realisation of accelerated economic growth and development as witnessed in Asia and Latin America. To do this, we are cognisant of the significance of attracting foreign investment for the country and any other developing country for that matter so as to be able to drive economic growth. The attraction of foreign investment is a mammoth challenge which would require a country to possibly outcompete other countries for it to attract significant investment. To this end we seek to look at corruption and competitiveness indices as a means towards determining how Botswana fares globally in relation to other countries in these respects. The thinking is that if the country has been going up the ranks in critical key areas, it could be able to out-compete some other countries in attracting foreign investment which it so desperately needs, ceteris paribus. We start off by looking at corruption and thereafter we look at competitiveness at macro levels, with the risk of leaving out critical information which may have helped in understanding more substantively the macro aspect.

\subsubsection{Corruption Rankings}

Corruption is a threat to the advancement of economies as it misappropriates incomes for personal gain that would have otherwise been used for the improvement of lives through economic growth and development. Botswana has however been a leader in the African continent for more than ten years as the least corrupt in Africa. Sadly, and most probably expectedly, it has in 2018 lost the first spot within the continent to Seychelles. Figure 6 shows Botswana's corruption rankings over the last ten years and this is compared to the rankings of Seychelles. The scores of Botswana are also included to give us a more in-depth understanding of the dynamics than would have been the case with the rankings only.

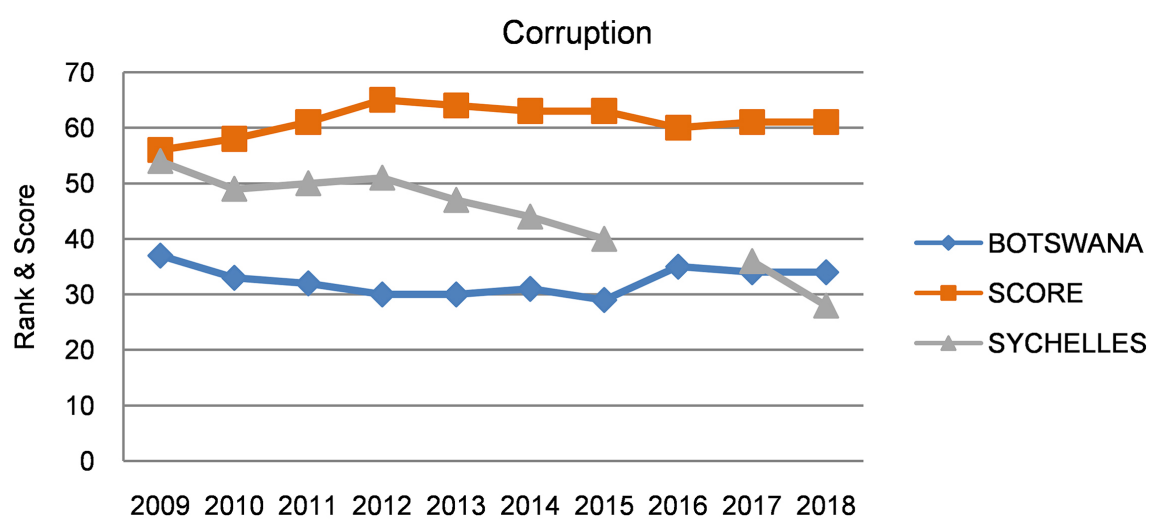

Figure 6. Corruption ranking for Botswana and Seychelles 2009-2018. 
Botswana was ranked $37^{\text {th }}$ in the world and the first in Africa with a score of 56 while Seychelles was ranked 54 ${ }^{\text {th }}$. Botswana's increased its score to 65 in 2012 and it experienced an improved ranking to 30. Seychelles also improved in its ranking to 51 in 2012. Botswana's improved ranking and an increase in its scores is a positive, which the country needed to build upon so as to boost investor confidence. The country was able to go up the ranks to a high of 29 over the period, albeit at a lower score of 63 . The simultaneous decrease in the scores and increase in the ranking may mean that the world may have gotten more corrupt over the period, while Botswana also increased its level of corruption it was outwitted by other countries. The country's ranking was 35 with a score of 60 in 2016 before rising to 34 in both 2017 and 2018 at a score of 61 . The ranking was on the average based on 183 countries.

The performance of Seychelles over the period is admirable. The country's rankings have been consistently improving on the average over the period under investigation. It would be expected that holding all things constant, the country should be able to have a greater appeal than Botswana in the attraction of investment. Botswana has not consistently improved over the period and if at all it did improve such is not significant both in terms of rankings and scores. The country may have lost its comparative advantage over the period to some countries which performed like Seychelles.

\subsubsection{Competition Rankings}

The literature on the demographic dividend is replete with the significant roles played by education/skills, health, economics and governance in driving economic growth availed by the window of opportunity. In this sub-section we attempt to look at some of those key pillars in determining how well we compete with other countries. The Global Competitiveness Index is a measure of national competitiveness that is a based on a set of institutions, policies and other factors, which determine the level of productivity [16]. In our analysis the ranking was based on 140 countries or there about.

Botswana's overall competitiveness ranking has actually been diminishing over the ten year period ranging from 2009 to 2018 from 56 to 90 . This is a very clear indication that we are losing the competitive edge we might have had in 2009. This does not augur well for a country at the centre of the dividend. Botswana's performance on the macroeconomic front has been very impressive at 41 in 2009, notwithstanding the outlier rankings of 2010 and 2011 which stood at 82 and 81 respectively. The ranking was 24 in 2012 before improving to position 1 in 2018. This is commendable performance with regard to the country's macroeconomic stability and probably the best ranking ever to be attained by an African country. We can only hope that the country does all that is necessary to maintain a comparable ranking going forward in the hope of enhancing opportunities for harnessing the dividend.

The country did fairly badly in the other pillars which drive the overall index. 
This is to be expected in view of the fact that the overall index is made up of the aggregation of all the other pillars and the country did badly at the collective level. The country's ranking on the institutional pillar has deteriorated from a best of 29 in 2009 to a worst of 62 in 2018. The efficiency of institutions is instrumental in the enhancement of governance and this deterioration spells doom for governance. At the time of the period under observation higher education and training, referred to his as skills, the country ranked at 94 , improving to 93 the subsequent year before going to a high of 101 in 2013 and a best of 92 in 2018. While there are isolated cases of improvement, such were marginal while the deteriorations were relatively significant. The country has consistently remained amongst the worst fifty percent performers throughout the entire period.

Additional information based on Botswana general certificate for secondary education (BGCSE), results indicate that those who passed their upper secondary school results with grade $\mathrm{C}$ or better in each of the last four years did not exceed 26 percent of all candidates. It needs to be noted that not all of these students qualify for admission into tertiary institutions. Surprisingly those in private schools continue to do very well in comparison to those in public school. This adversely affects the poor who cannot afford private schools and these will perpetuate a vicious circle of poverty amongst the poor. Education and skills are quite critical in the attainment of growth occasioned by the dividend. However, the country has not been doing well on this area.

The area of health is one in which the country's performance ranks the worst of all the pillars (Figure 7). Of a total of 140 countries, the country has at best outperformed 33 countries and at worst only 13 countries. The realisation of the dividend requires a vibrant health sector and ours seem not to be ideal in complementing other drivers of the economy. The health sector needs to be upped up to help increase productivity and school performance amongst other considerations. The country was ranked 118 in 2009 and its worst ranking at 127 in 2013 before improving to 107 in 2016. Infrastructure rankings have also worsened over time from 61 in 2009 to 108 in 2018. Infrastructural development is considered a positive determinant of foreign direct information and its continued deterioration doesn't augur well for the country's window of opportunity.

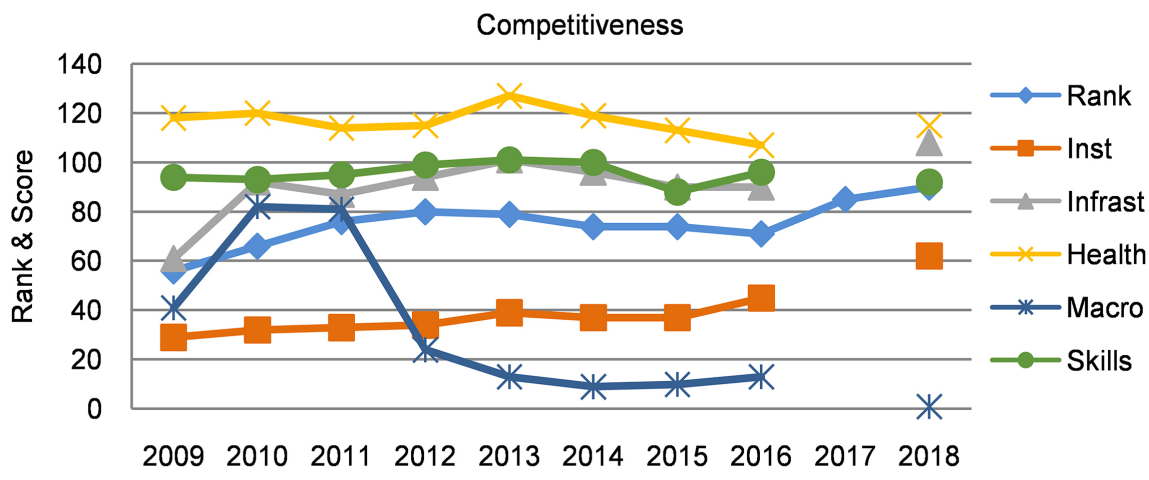

Figure 7. Botswana's competitiveness ranking 2009-2018. 


\section{Discussion}

Botswana's loss of being the least corrupt country in Africa would not come as surprise to many who have closely observed the operations of government in the not so distant past. The appropriation of the over sight institutions by the precedency was bound to suffocate their independence and render them ineffective in carrying out their core mandates. In particular, one security organ was more of a law unto itself and there are indications now, following the change of baton at the presidential level, that a lot of national resources may have been embezzled.

Where independence of oversight institutions is compromised and corruption reigns supreme, it would be expected that governance will be highly eroded. This erosion of good governance that the country has for many years been known for has been recently been confirmed by the current president. Giving a press conference recently he mentioned that we have had an oppressive government in the last decade or so. This is indictment on a country, which for a long time has been perceived an African leader on democracy and good governance. However, such observation resonates well with the competitiveness and corruption analysis above. Botswana shift to some autocratic rule will need to be reigned upon and the democratic culture restored for the country to advance.

While there are indications that corruption has been on an upsurge, evidence exists to the effect that some of state owned enterprises embroiled in corruption cases have been prune to underperformance and loss making compared to those not implicated [17]. This clearly shows the debilitating effects of corruption on service delivery. There are reported cases of a cabinet minister who alleged that his corruptive tendencies are not the worst as they those within other ministries worse than him

\section{Conclusion}

Botswana has entered the window of opportunity driven by conscious and concerted effort by the government through family planning initiatives following independence. The country invested in human capital through both education and health even though the quality of health and education seems to be below par. The government should capitalize on this window of opportunity given by the demographic dividend in order to speed up its developmental process and thus emulate the Asian Tigers and Latin America. The country's corruption ranking may not be as bad as that for competitiveness, but it is certainly compromised by a conscious decision to render it dependent on the presidency. These have had adverse effects on governance and delivery of services by the public sector, hence the dismal performance of students within the government schools and poor health sector. The country runs the risk of losing out on the dividend unless a concerted effort to correct the wrongs is taken as a matter of urgency. The greatest victims from these inefficiencies will be the poor whose poverty will not only be aggravated, but the inequalities will worsen. The work- 
ing class may transit into old age as paupers without a hope, having either not worked or having done so only briefly. There is a need for action.

\section{Acknowledgements}

I am highly indebted to UNFPA, Gaborone Office, for the financial assistance which enabled me to present in the Ghana Population conference 2019. I am also thankful for the invaluable comments by Boago Mokatane.

\section{Conflicts of Interest}

The author declares no conflicts of interest regarding the publication of this paper.

\section{References}

[1] Todaro, M.P. and Smith, S.C. (2009) Economic Development. 10th Edition, Pearson Education Limited, London.

[2] UNFPA (2017) The State of World Population 2017. Worlds Apart, Reproductive Health and Rights in an Age of Inequality.

[3] Magang, D. (2015) Delusions of Grandeur: Paradoxies and Ambivalences in Botswana's Macroeconomic Firmament. Print Media Consult, Gaborone.

[4] Choia, Y. (2013) Demographic Transition in Sub-Saharan Africa: Implications for Demographic Dividend. Working Paper Drafted for Presentation and Discussion at the IUSSP 2013 Meeting. US Agency for International Development.

[5] Gribble, J.N. and Bremner, J. (2012) Achieving a Demographic Dividend. Population Bulletin, 67, 1-15.

[6] Bloom, D.E., Canning, D. and Sevilla, J. (2001) Economic Growth and the Demographic Transition. National Bureau of Economic Research, Cambridge, Working Paper 8685. http://www.nber.org/papers/w8685

[7] Bloom, D.E., Canning, D., Fink, G. and Finlay, J. (2007) Realizing the Demographic Dividend: Is Africa Any Different? Program on the Global Demography of Aging. Harvard University, Cambridge.

[8] Adjor, D.M. and Kebalo, L. (2018) Does Corruption Matter for Unemployment in SADC Countries? Review of Economic and Business Studies, 11, 65-92. https://doi.org/10.1515/rebs-2018-0074

[9] AFIDEP (2018) Opportunities and Policy Actions to Maximise the Demographic Dividend in Botswana. Demographic Dividend Study Report.

[10] Leburu, V., El-Halabi, S., Mokganya, L. and Mills, S. (2009) The Contribution of the Botswana Family Planning Program to the Largest Fertility Decline in Sub-Saharan Africa.

[11] Central Statistics Office (1995) Population Report 1989-1991.

[12] Statistics Botswana (2018) Botswana Demographic Survey 2017.

[13] Statistics Botswana (2006) Botswana Demographic Survey 2006.

[14] Statistics Botswana (2007) Botswana Family Health Survey 2007.

[15] Malema, B.W. (2012) Botswana's Formal Economic Structure as a Possible Source of Poverty: Are There Any Policies Out of This Economic Impasse? Pula: Botswana Journal of African Studies-Special Issue on Botswana Economy, 26, 51-69. 
[16] Schwab, K. (2018) The Global Competitiveness Report 2017-2018. World Economic Forum.

[17] Malema, B.W. (2014) Public Enterprises' Performance Is a Significant Function of Government's Behavior. Stanbic Quarterly Economic Review, First Issue. 